\title{
Congenital Bimelic Hypertrophy of the Hands
}

\author{
Tugba Kalay $^{\mathrm{a}}$ H. Jacobus Gilhuis ${ }^{\mathrm{a}}$ Gerald Kraan $^{\mathrm{b}} \quad$ Nens vanAlfen $^{\mathrm{c}}$ \\ ${ }^{a}$ Department of Neurology, and ${ }^{b}$ Orthopedic Surgery, Reinier de Graaf Gasthuis, Delft, and \\ 'Department of Neurology, Radboud University Medical Centre, Nijmegen, The Netherlands
}

\section{Key Words}

Congenital hypertrophy $\cdot$ Hands $\cdot$ Bilateral involvement

\begin{abstract}
Congenital hypertrophy of the hand is a rare phenomenon. The condition is characterized by hypertrophy of muscles, varies in severity and has been reported under different names. Some patients also have aberrant muscles. Electromyography is unremarkable, and the signal intensity on MRI and ultrasound is normal. The etiology is unknown and does not seem to be confined to a peripheral nerve, part of the plexus or nerve root. The condition is assumed to be congenital. We report a 28-year-old male with asymmetric hypertrophy of both hands and give a review of the 4 other cases known so far.

(C) 2016 The Author(s)

Published by S. Karger AG, Basel
\end{abstract}

\section{Introduction}

Congenital hypertrophy of the upper extremity is a rare, nonprogressive phenomenon, involving the hand and forearm and sometimes the whole extremity. Bilateral involvement is even rarer. We report a 28-year-old male with hypertrophy of both hands to illustrate this unusual clinical syndrome.

\section{Case Presentation}

A 28-year-old, right-handed, healthy male had been suffering from pain and cramping sensations in both his hands for years since working as a crane driver. His work involved operating a crane with a joystick in each hand. As long as he could remember, he had had big hands compared to those of his peers of the same age. He had no other symptoms. Family

\begin{tabular}{ll}
\hline ARGER & Tugba Kalay, MD \\
& Maastricht University Medical Center \\
& P. Debyelaan 25 \\
& NL-6229 HX Maastricht (The Netherlands) \\
E-Mail tugba.kalay@mumc.nl
\end{tabular}


Kalay et al.: Congenital Bimelic Hypertrophy of the Hands

history of neuromuscular diseases or congenital abnormalities was negative. Physical examination revealed an increased muscle bulk of both hands and the right forearm, with the right hand being slightly bigger than the left hand. In particular, both abductor pollicis muscles, the dorsal intrinsic hand muscles, and the abductor digiti quinti showed an increased muscle belly volume (fig. 1). Motor and sensory functions of the hands were normal, as was the rest of the neurological examination. His feet and jaw were of normal proportions.

Laboratory tests, including sedimentation rate and creatine phosphokinase revealed no abnormalities. T1- and T2-weighted MRI showed diffuse enlargement of the muscle mass, in particular of both abductor pollicis muscles, the intrinsic muscles, the abductor digiti quinti, and the right forearm flexor compartment (fig. 2, fig. 3). The maximal axial diameters of the muscle belly of the first dorsal interosseus muscles were $24 \times 16 \mathrm{~mm}$ (right) and $25 \times 18 \mathrm{~mm}$ (left). The only normal values we could find in the literature were from 5 healthy males who had a muscle belly width of $9.6 \pm 0.5 \mathrm{~mm}$ on ultrasound (mean of radial and ulnar muscle proportion). There are no normal values known for the abductor pollicis muscle $[1,2]$. The right forearm axial diameter measured at maximum $(10 \mathrm{~cm}$ from the elbow) $54.75 \times 53.12$ $\mathrm{mm}$, compared to $50.04 \times 50.58 \mathrm{~mm}$ for the left arm. The muscles had a normal density without signs of architectural change, fatty infiltration, tumors, or fluid accumulation. Visual ultrasound assessment also showed a normal echogenicity (i.e. Heckmatt grade I) of the muscles. X-ray examination revealed no bony abnormalities. Nerve conduction studies were unremarkable for median and ulnar nerve amplitudes and conduction velocities. Needle electromyography examination of the right abductor pollicis brevis, biceps brachii, left extensor digitorum communis, abductor pollicis brevis, and abductor digiti minimi showed sporadic polyphasic, large motor unit potentials with a normal interference pattern. Because of the mild enlargement, its nonprogressive nature, and the absence of other abnormalities, no further workup (such as muscle biopsy or search for a somatic mutation in PIK3CA) was performed.

On the basis of the patients' history, physical examination, and imaging, a congenital hypertrophy of both hands and the right forearm was diagnosed. Given the work-related nature of the symptoms, he was referred to a rehabilitation physician who successfully instructed him how to avoid cramps and pain.

\section{Discussion}

Idiopathic hypertrophy of an upper extremity is a rare phenomenon. So far, only 17 cases have been described in the German and English medical literature. The condition varies in severity and has been reported under different names, such as aberrant muscle syndrome and congenital monomelic hypertrophy [2-8]. On MRI and ultrasound, muscle tissue is characterized by normal signal intensity and architecture [4]. The condition is most likely not due to selective hypertrophy (i.e. a training effect) but to a local increase in muscle mass because of a local genetic variation or mosaicism affecting the growth rate. The etiology of this focal muscle bulk increase is unknown and does not seem to be confined to a peripheral nerve, part of the plexus, or nerve root territory, i.e. neurogenic hypertrophy. We assume the condition to be congenital and not acquired. Previous (unilateral) cases told a similar story with old photos as evidence $[4,5]$.

Cases of bilateral involvement have been described four times so far (table 1) [1, 6, 9, 10]. In the 3 adult cases, only the first dorsal interosseus muscles were involved, whereas our patient had diffuse involvement of all hand muscles, with prominence of the abductor 
Kalay et al.: Congenital Bimelic Hypertrophy of the Hands

pollicis muscles. To our knowledge, this is the first adult case in which a bilateral diffuse involvement of muscles of the hand is described.

Biopsies (from unilateral cases) showed only a slightly more-than-normal variation in fiber size, without signs of inflammation, pathological blood vessels, fibrosis, or loss of muscle fibers. Changes indicating denervation were absent $[1,4,7,8]$.

The syndrome is distinctly different from other causes of hand or upper-limb hypertrophy such as Proteus syndrome or Freeman-Sheldon syndrome. These syndromes come with a multitude of malformations and tissue overgrowth [11]. Other possible causes such as nerve hamartomas are progressive in nature, and were excluded by imaging. Muscle hypertrophy due to nerve damage, so-called neurogenic pseudohypertrophy, is electromyographically characterized by early recruitment of large motor unit potentials at a high firing rate. Only muscles innervated by the specific damaged nerve are enlarged in those cases [7, 12].

In adults, hypertrophy does not affect daily activities as long as they are not working. Surgery does not always result in satisfactory corrections. Decreasing the muscle volume (including the excision of possible aberrant muscles) is therefore only recommended for cosmetic purposes [5]. Instructions and avoidance of heavy manual labor are usually enough to alleviate the symptoms. Although rare, congenital monomelic hypertrophy should be considered in the differential diagnosis of the hypertrophied hand. Bilateral involvement is also possible.

\section{Acknowledgement}

The authors thank J. Reijnen, radiologist, for her analysis of the MRI and ultrasound imaging.

\section{Statement of Ethics}

The patient gave his permission for using the images of his hands.

\section{Disclosure Statement}

The authors report no conflicts of interest relevant to the paper.

\section{References}

1 Mirastschijski U, Damert HG, Mawrin C, Schneider W: Myopathic changes in bilateral hypertrophy of the first interosseus muscle of the hand. J Neurol 2009;256:1551-1554.

-2 Atroshi L, Persson PE: Idiopathic hypertrophy of the first dorsal interosseous and thenar muscles presenting as a tumor in a 12-year-old boy. Acta Orthop 2005;76:939-940.

-3 Clay NR, Austin S: Idiopathic thenar muscle hypertrophy. J Hand Surg (Br) 1988;13:100-101.

4 Gilhuis HJ, Zöphel OT, Lammens M, Zwarts MJ: Congenital monomelic hypertrophy of the upper extremity. J Neuromuscul Dis 2009;19:714-717.

5 Gilhuis HJ, Rafiee M, Zwarts MJ: Unilateral upper limb muscular hyperplasia. Neurol 2013;80:E170-E171.

-6 Ogino T, Satake H, Takahara M, Kikuchi N, Watanabe T, Iba K, Ishii S: Aberrant muscle syndrome: hypertrophy of the hand and arm due to aberrant muscles with or without hypertrophy of the muscles. Congenit Anom 2010;50:133-138.

7 Takka S, Kazutera D, Hattory Y, Kitajiima I, Sano K: Proposal of new category for congenital unilateral upper limb muscular hypertrophy. Ann Plast Surg 2005;54:97-102.

8 Tanabe K, Tada K, Doi T: Unilateral hypertrophy of the upper extremity due to aberrant muscles. J Hand Surg 1997;22:253-257. 


\section{Case Reports in Neurology}

\begin{tabular}{l|l}
\hline \multicolumn{2}{l}{ Case Rep Neurol 2016:8:34-38 } \\
\hline DOI: $10.1159 / 000443326$ & $\begin{array}{l}\text { (c) 2016 The Author(s). Published by S. Karger AG, Basel } \\
\text { www.karger.com/crn }\end{array}$ \\
\hline
\end{tabular}

Kalay et al.: Congenital Bimelic Hypertrophy of the Hands

9 Peh WCG, Ip, WI, Wong LLS: Diagnosis of dorsal interosseous pseudotumours by magnetic resonance imaging. Australas Radiol 1999,43:394-396.

10 Boelmans K, Fischbach F, Mirastschijski U, Vielhaber S: Bilateral ideopathic hypertrophy of the first dorsal interosseous muscles in a 43-year-old man. J Neurol Neurosurg Psychiatry 2008;79:996.

11 Satter E: Proteus syndrome: 2 case reports and a review of the literature. Cutis 2007;80:297-302.

-12 Mattle HP, Hess CW, Ludin HP, Mumenthaler M: Isolated muscle hypertrophy as a sign of radicular or peripheral nerve injury. J Neural Neurosurg Psychiatry 1991;54:325-329.

Table 1. Clinical features of reported cases

\begin{tabular}{lccll}
\hline First author [Ref.] & Sex & Age, years & Muscle & Other characteristics \\
\hline Mirastschijski [1] & M & 44 & $1^{\text {st }}$ dorsal interosseus & Biopsy, myopathic changes, fiber size varying \\
Ogino [6] & M & 3 & Thenar and hypothenar & Ulnar deviation \\
Peh [9] & M & 38 & $1^{\text {st dorsal interosseus }}$ & Left side bigger \\
Boelmans[10] & M & 43 & $1^{\text {st dorsal interosseus }}$ & Electromyography normal \\
Present case & M & 28 & Thenar, hypothenar and right forearm & MRI and ultrasound normal \\
& & & & Electromyography normal \\
\hline
\end{tabular}

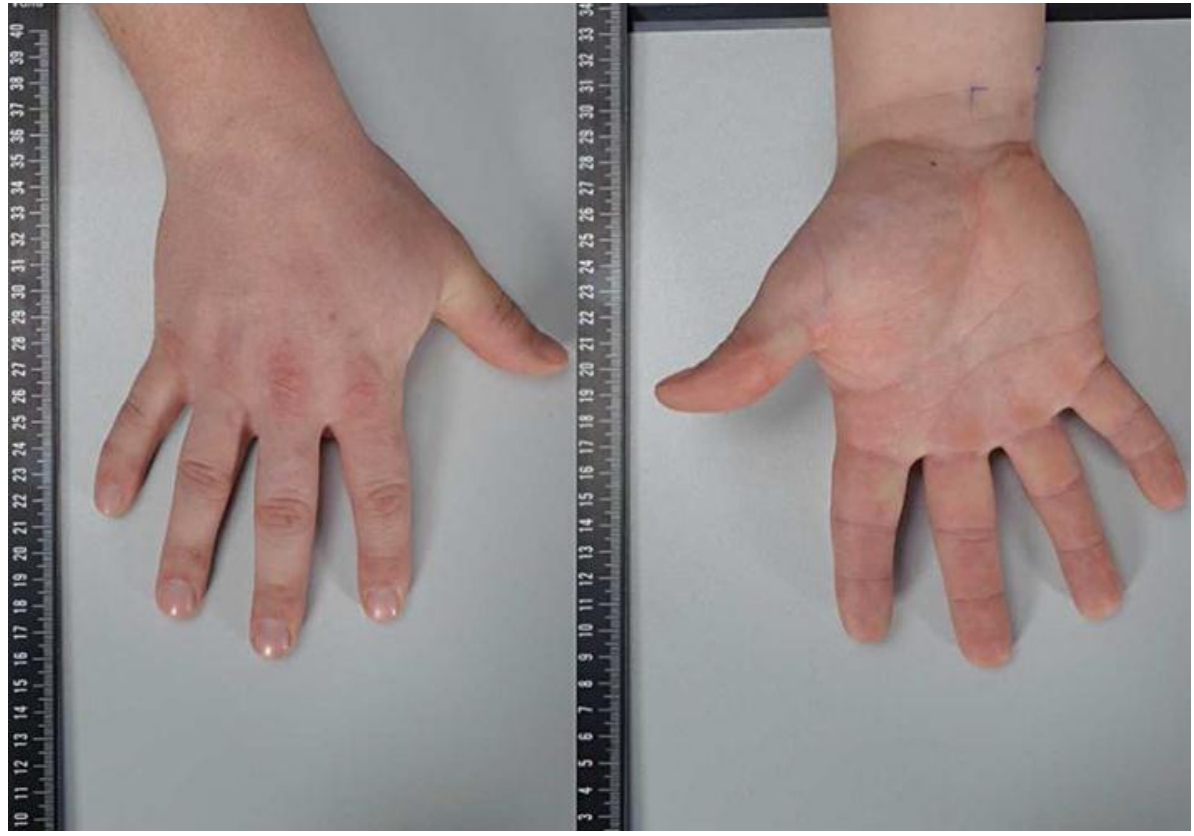

Fig. 1. Increased muscle belly of the thenar and hypothenar regions without an ulnar deviation of the fingers (right hand). 


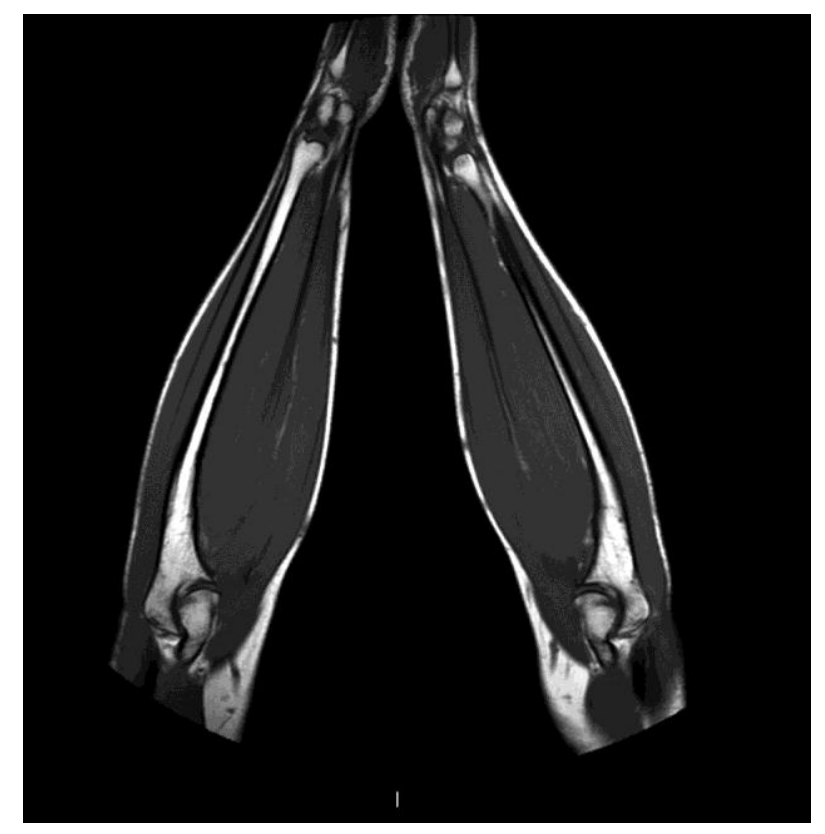

Fig. 2. T1-weighted MRI, showing diffuse enlargement of the muscles of the right forearm.

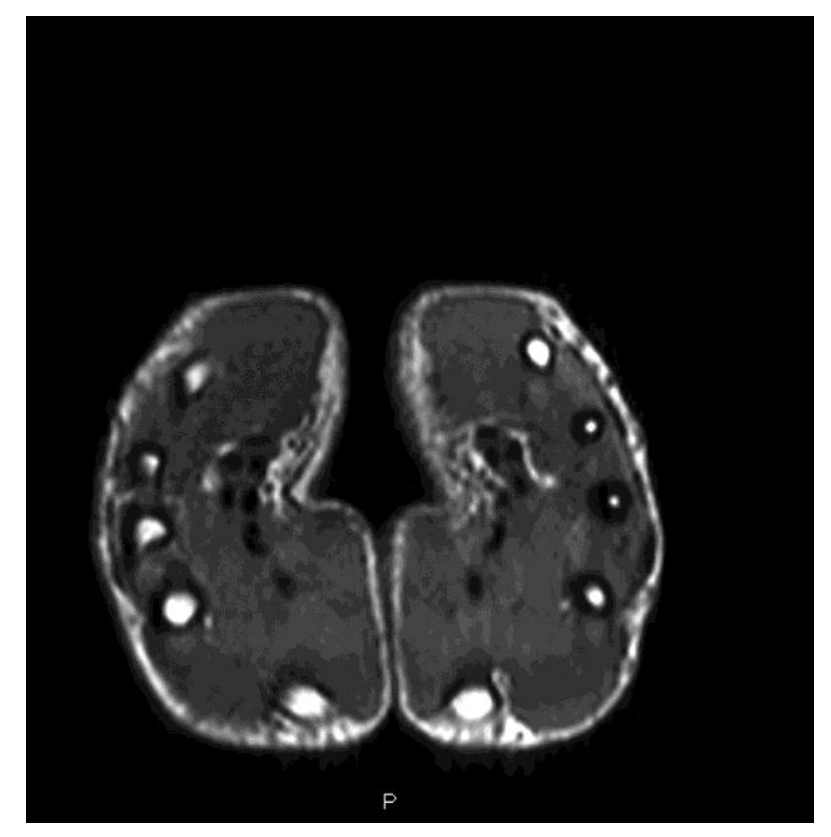

Fig. 3. T1-weighted MRI, showing diffuse enlargement of the muscles of the hands. 